\title{
THE
}

\section{New Micropeptins with Anti-Neuroinflammatory Activity Isolated from a Cyanobacterial Bloom}

Riley D. Kirk

University of Rhode Island

Haiyin $\mathrm{He}$

Paul G. Wahome

ShiBiao Wu

Guy T. Carter

See next page for additional authors

Follow this and additional works at: https://digitalcommons.uri.edu/bps_facpubs

Creative Commons License

cc) (i) $\Theta$

This work is licensed under a Creative Commons Attribution-Noncommercial-No Derivative Works 4.0 License.

\section{Citation/Publisher Attribution}

Kirk, R. D., He, H., Wahome, P. G., Wu, S., Carter, G. T., \& Bertin, M. (2021). New Micropeptins with AntiNeuroinflammatory Activity Isolated from a Cyanobacterial Bloom. ACS Omega. In press. doi: 10.1021/ acsomega.1c02025

Available at: https://doi.org/10.1021/acsomega.1c02025

This Article is brought to you for free and open access by the Biomedical and Pharmaceutical Sciences at DigitalCommons@URI. It has been accepted for inclusion in Biomedical and Pharmaceutical Sciences Faculty Publications by an authorized administrator of DigitalCommons@URI. For more information, please contact digitalcommons-group@uri.edu. 


\section{Authors}

Riley D. Kirk, Haiyin He, Paul G. Wahome, ShiBiao Wu, Guy T. Carter, and Matthew Bertin 
This document is the Accepted Manuscript version of a Published Work that appeared in final form in ACS Omega, copyright $\odot$ American Chemical Society after peer review and technical editing by the publisher. To access the final edited and published work see https://doi.org/10.1021/acsomega.1c02025.

\title{
New Micropeptins with Anti-Neuroinflammatory Activity Isolated from a Cyanobacterial Bloom
}

\author{
Riley D. Kirk, ${ }^{\dagger}$ Haiyin He, ${ }^{\ddagger}$ Paul G. Wahome, ${ }^{\ddagger}$ ShiBiao Wu,$\stackrel{\ddagger}{\ddagger}$ Guy T. Carter,${ }^{\ddagger}$ and Matthew J. Bertin ${ }^{\dagger} * *$ \\ ${ }^{\dagger}$ Department of Biomedical and Pharmaceutical Sciences, College of Pharmacy, University of Rhode Island, Kingston, RI 02881, USA \\ ${ }^{\ddagger}$ Biosortia Pharmaceuticals Hollings Marine Laboratory, Charleston, SC 29412, USA \\ *Correspondence: mbertin@uri.edu; Tel.: +1-401-874-5016
}

\begin{abstract}
Metabolite mining of environmentally collected aquatic and marine microbiomes offers a platform for the discovery of new therapeutic lead molecules. Combining a pre-fractionated chromatography library with LC-MS/MS-based molecular networking, and biological assays, we isolated and characterized two new micropeptins ( $\mathbf{1}$ and $\mathbf{2}$ ) along with the previously characterized micropeptin 996. These metabolites showed potency in anti-neuroinflammatory assays using BV-2 mouse microglial cells, showing 50\% reduction in inflammation in a range from 1-10 $\mu \mathrm{M}$. These results show promise for cyanobacterial peptides in the therapeutic realm apart from their impact in environmental health, and provide another example of the utility of large pre-fractionated natural product libraries for therapeutic hit and lead identification.
\end{abstract}




\section{INTRODUCTION}

Neuropathic pain, or nerve pain, resulting from damage to or dysfunction of the somatosensory nervous system is notoriously difficult to treat. Neuroinflammation is key in the initiation and persistence of neuropathic pain. ${ }^{1}$ Recent research has shown that the prevalence of neuropathic pain in the United States is approximately $10 \%$ of adults, and out of those reporting neuropathic pain over $40 \%$ were treating with either weak or strong opioid drugs. ${ }^{2}$ This prevalence of neuropathic pain increases in specific cohorts with $33 \%$ of those with chronic back pain displaying characteristic signs of neuropathic pain. ${ }^{3}$ Additionally, chronic, uncontrolled neuroinflammation is an indicative sign of neurodegenerative diseases such as Alzheimer's Disease and Parkinson's Disease. ${ }^{4,5}$ Our group is interested in the discovery of new specialized metabolites from marine and aquatic microbiomes that are effective in reducing neuroinflammation. While we have had some success in this approach by mining marine cyanobacterial blooms for anti-neuroinflammatory agents, ${ }^{6}$ freshwater cyanobacterial blooms offer additional chemical space for discovery, especially in terms of cyclic peptides. ${ }^{7}$ These peptides belong to several classes including the microcystins, aeruginosins, microginins, anabaenopeptins, micropeptins, microviridins and cyclamides. More than 600 peptides and peptidic compounds have been described from various cyanobacterial taxa. ${ }^{7}$ Many of these peptides are hepatotoxic, such as the microcystins, which can cause non-alcoholic liver disease and acute liver failure. ${ }^{8,9}$ Consumption of contaminated drinking water is considered the major route of human exposure to microcystins, and the EPA has set concentration limits on these toxins $(1.6 \mu \mathrm{g} / \mathrm{L}=$ Do Not Drink; $20 \mu \mathrm{g} / \mathrm{L}=$ Do Not Use). While neurotoxins and hepatotoxins are a significant public health concern, these blooms are comprised of a complex milieu of taxonomically diverse microbes, each possessing various biosynthetic capabilities. Large scale biomass sampling from groups like Biosortia have revealed freshwater cyanobacterial blooms are more chemically complex than previously assumed, and novel molecules with potent biological activities can be isolated and characterized. ${ }^{10,11}$ Work on this 'metabolite mining' from complex aquatic microbiomes envisions the bloom environment as an ecosystem level complex co-culture experiment in which the aquatic microbiome is producing an equally complex suite of secondary metabolites.

The use of prefractionated natural product libraries has shown promise in increasing the potential of identifying lead structures following a bioassay-guided discovery approach. ${ }^{12}$ Biosortia Pharmaceuticals has generated a prefractionated library from cyanobacterial biomass dominated by Microcystis aeruginosa originally isolated from a wastewater management facility in Muskegon, Michigan. Previous mining of this material resulted in the isolation and structure elucidation of new highly cytotoxic microcystin toxins. ${ }^{10}$ A similar workflow was implemented for biomass collected from Grand Lake St. Mary's in Ohio, and this effort resulted in the identification and characterization of the exquisitely potent cyanobufalin toxins. ${ }^{11}$ Each chromatography fraction in the library contained a rarefied mixture of chemicals allowing hits to be identified from less complex starting material compared to crude extracts or more complex fractions. Pairing the prefractionated library with metabolite profiling tools such as LC-MS/MSbased molecular networking afforded the opportunity for rapid annotation and dereplication. ${ }^{13}$ Implementing these approaches allowed our group to isolate and characterize two new micropeptins (1 and 2) and the previously discovered micropeptin 996 (Figures 1 and S1). All three metabolites showed potent inhibition of the inflammatory response in BV-2 murine microglial cells. 


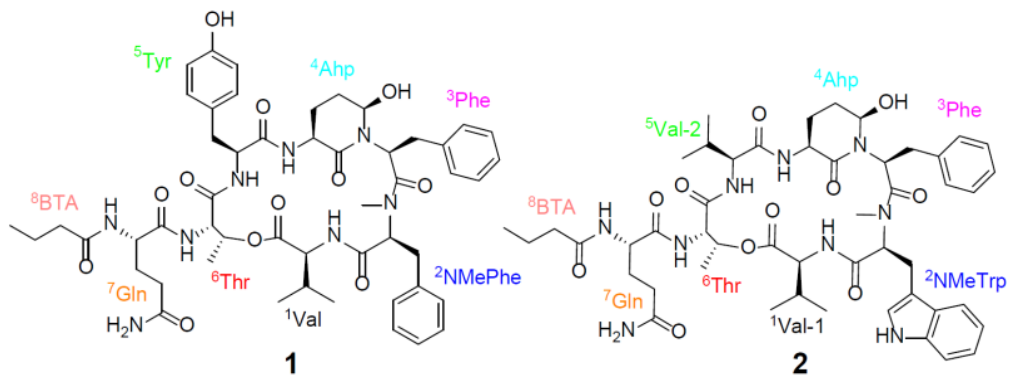

Figure 1. Structures of micropeptins 982 (1) and 957 (2).

\section{RESULTS AND DISCUSSION}

Structure Elucidation of Micropeptin 996, 1 and 2. Biosortia's chromatography fraction library consisted of over 150 individual samples each with a rarefied collection of microbial metabolites. Following a bioassay-guided isolation approach, we prioritized fractions with low cytotoxicity and strong anti-inflammatory effects in the BV-2 murine microglial cell line. Fraction D29 showed no significant cytotoxicity and inhibited the production of nitric oxide species (NOS) in the cells by greater than $50 \%$ at a $10 \mu \mathrm{g} / \mathrm{mL}$ dose (Figures $\mathrm{S} 2$ and S3).

While we were using a pre-fractionated library for screening, the samples were still relatively complex, likely due to the complex consortia of bacteria and other microbes in the original biomass. In order to rapidly annotate and visualize the chemical space in the fraction of interest (D29), we subjected the fraction to LC-MS/MS analysis followed by molecular networking. The resultant network showed five separate clusters with clusters 1 and 2 showing 15 and 9 individual nodes, respectively and parent masses between $\mathrm{m} / \mathrm{z}$ 900-1100 (Figure S4). Comparing precursor $\mathrm{m} / \mathrm{z}$ values and previous molecular networks available in the literature, we putatively identified the metabolites in clusters 1 and 2 as micropeptins or cyanopeptolins. ${ }^{14,15}$ Node 1019 and 1005 showed high ion counts in mass spectrometry analysis and were abundant in the HPLC chromatogram and these metabolites were targeted for isolation (cf. Figure 2, S4, and S5).

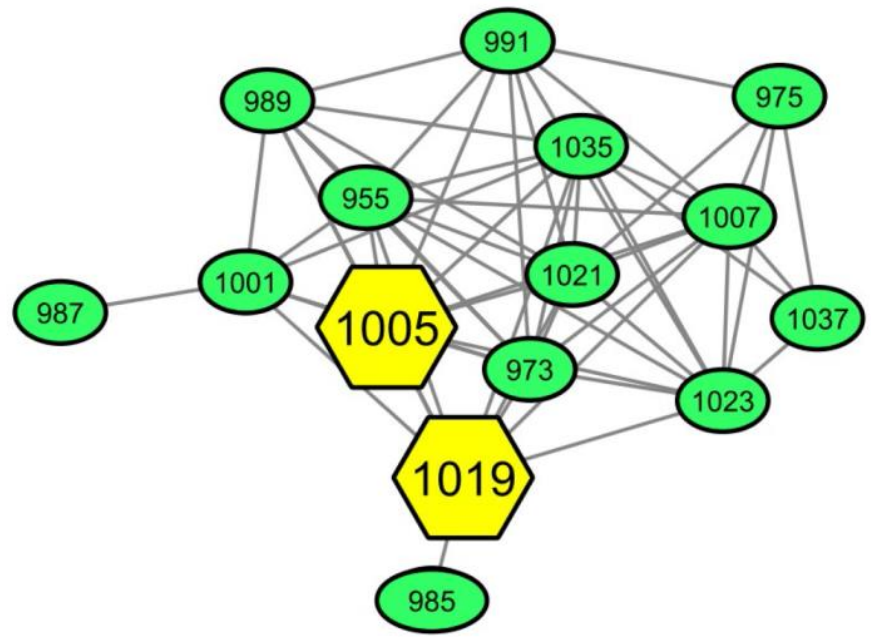

Figure 2. Molecular networking cluster showing micropeptin 982 (1) and micropeptin 996 as

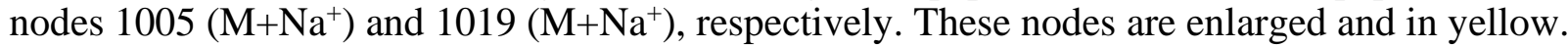

Following examination of the molecular networks, additional chromatographic procedures and testing led to the isolation of three metabolites (Figures S5 and S6). ${ }^{1} \mathrm{H}$ NMR and ${ }^{13} \mathrm{C}$ NMR 
analysis indicated that these molecules were peptidic in nature and that they were closely related to each other in chemical structure (cf. Figures S7, S8, S11, S12, and S20).

The first metabolite of interest (Fraction D29, peak 7) gave an $\mathrm{m} / \mathrm{z}$ of $1019.4854[\mathrm{M}+\mathrm{Na}]^{+}$ following HRESIMS analysis suggesting a molecular formula of $\mathrm{C}_{52} \mathrm{H}_{68} \mathrm{~N}_{8} \mathrm{O}_{12}$ (Figure S9). Dereplication efforts based on mass spectrometry data (Figures S9 and S10) identified micropeptin 996 as the likely metabolite and further examination of ${ }^{1} \mathrm{H}$ NMR and ${ }^{13} \mathrm{C}$ NMR spectra confirmed the identification as these data matched the previously published data exactly. ${ }^{16}$

The second metabolite (1) (Fraction D29, peak 6.1) gave an $\mathrm{m} / z$ of $1005.4698[\mathrm{M}+\mathrm{Na}]^{+}$ following HRESIMS analysis suggesting a molecular formula of $\mathrm{C}_{51} \mathrm{H}_{66} \mathrm{~N}_{8} \mathrm{O}_{12}$ and 23 degrees of unsaturation (Figure S18). Dereplication efforts did not readily identify a known micropeptin with this $m / z$ value. The molecule was 14 Da less than micropeptin 996 and the ${ }^{1} \mathrm{H} \mathrm{NMR}$ and ${ }^{13} \mathrm{C} \mathrm{NMR}$ spectra of 1 and micropeptin 996 were nearly identical and the presumption was a difference of a $\mathrm{CH}_{2}$ group between the two compounds. Examination of 2D NMR data including HSQC, HMBC, COSY, TOCSY, and NOESY spectra (Table 1 and Figures S1 and S13-S17) established spin systems and connections for the following sequence of amino acids: valine, $N$-methyl phenylalanine, phenylalanine, amino hydroxy piperidone (Ahp), tyrosine, threonine, glutamine, and butyric acid. The difference being the substitution of a tyrosine in $\mathbf{1}$ for the homotyrosine in micropeptin 996. The planar structure of 1 was also supported by MS/MS fragmentation data, which identified a key fragment $\left(m / z\right.$ 404.1832) as Ahp-Phe- $N-M e P h e-\mathrm{H}_{2} \mathrm{O}$ (Figure S19). ${ }^{16}$ The relative configuration of the Ahp residue was assigned based on NOE correlations between $\mathrm{H}-$ 2 Ahp, $\mathrm{H}-4 \mathrm{a}_{\mathrm{Ahp}}$, and $\mathrm{H}-5_{\text {Ahp }}$ showing that these hydrogens were co-planar. Additionally, the $\mathrm{NH}$ proton of the Ahp residue showed an NOE correlation to $\mathrm{H}-3 \mathrm{a}_{\mathrm{Ahp}}$, which showed an NOE correlation to the $\mathrm{OH}$ group attached to $\mathrm{C}-5_{\text {Ahp }}$ (Figure $\mathrm{S} 1$ ). This was consistent with previously publised research assigning the relative configuration of the Ahp residue. ${ }^{16,17}$ Compound 1 was given the name micropeptin 982 , which is a general convention to designate these micropeptins by molecular weight.

Table 1. NMR data for micropeptin $982(\mathbf{1})\left(500 \mathrm{MHz}\right.$ for ${ }^{1} \mathrm{H}$ NMR, $125 \mathrm{MHz}$ for ${ }^{13} \mathrm{C}$ NMR; DMSO- $\left.d_{6}\right)$.

\begin{tabular}{ccccc}
\hline Position & $\boldsymbol{\delta} \mathbf{c}$, mult & $\boldsymbol{\delta}_{\mathbf{H}}$, mult, $\boldsymbol{J}(\mathbf{H z})$ & HMBC & COSY \\
\hline Val-1 & $171.9, \mathrm{C}$ & & 1 & 3 \\
2 & $55.8, \mathrm{CH}$ & $4.65, \mathrm{dd}(9.6,4.5)$ & & 4,5 \\
3 & $30.8, \mathrm{CH}$ & $2.00, \mathrm{~m}$ & $1,2,3,5$ & 3,5 \\
4 & $19.1, \mathrm{CH}_{3}$ & $0.84, \mathrm{~d}(6.8)$ & $2,3,4$ & 2 \\
5 & $17.2, \mathrm{CH}_{3}$ & $0.70, \mathrm{~d}(6.8)$ & $N$-MePhe- 1 & $3 \mathrm{a}, 3 \mathrm{~b}$ \\
$\mathrm{NH}$ & & 7.42 (ovlp) & & $2,3 \mathrm{~b}$ \\
$N$-MePhe- & $168.8, \mathrm{C}$ & & $4,5,9$ & $2,3 \mathrm{a}$ \\
2 & $60.5, \mathrm{CH}$ & 5.01, ovlp & $2,4,5,9$ & 6,8 \\
$3 \mathrm{a}$ & $33.8, \mathrm{CH}_{2}$ & $3.20, \mathrm{~m}$ & & 5,9 \\
$3 \mathrm{~b}$ & & 2.84, ovlp & $6,7,8$ & 6,8 \\
4 & $137.7, \mathrm{C}$ & & $4,5,9$ & \\
$5 / 9$ & $129.7, \mathrm{CH}$ & $7.23, \mathrm{~d}(7.3)$ & 6,8 & $3 \mathrm{a}, 3 \mathrm{~b}$ \\
$6 / 8$ & $129.3, \mathrm{CH}$ & $7.39, \mathrm{~m}$ & & $2,3 \mathrm{~b}$ \\
7 & $126.3, \mathrm{CH}$ & $7.30, \mathrm{t}(7.4)$ & 1 & $2,3 \mathrm{a}$
\end{tabular}




\begin{tabular}{|c|c|c|c|c|}
\hline 4 & $136.5, \mathrm{C}$ & & & \\
\hline $5 / 9$ & $129.2, \mathrm{CH}$ & $6.77, \mathrm{~m}$ & 7 & 6,8 \\
\hline $6 / 8$ & 127.7, CH & 7.17, d (7.4) & $4,5,9$ & 5,9 \\
\hline 7 & $126.2, \mathrm{CH}$ & $7.13, \mathrm{~d}(7.1)$ & 5,9 & \\
\hline Ahp-1 & $168.9, \mathrm{C}$ & & & \\
\hline 2 & $48.8, \mathrm{CH}$ & $3.59, \mathrm{~m}$ & 1 & 3a,3b,Ahp-NH \\
\hline $3 a$ & $21.4, \mathrm{CH}_{2}$ & $2.40, \mathrm{~m}$ & & $2,3 b, 4 a, 4 b$ \\
\hline $3 b$ & & $1.61, \mathrm{~m}$ & & $2,3 \mathrm{a}$ \\
\hline $4 a$ & $29.1, \mathrm{CH}_{2}$ & $1.68, \mathrm{~m}$ & & $3 a, 4 b, 5$ \\
\hline $4 \mathrm{~b}$ & & $1.50, \mathrm{~m}$ & & $3 a, 4 a, 5$ \\
\hline 5 & 73.7, $\mathrm{CH}$ & 5.02, ovlp & & 4a,4b,Ahp-OH \\
\hline $\mathrm{NH}$ & & $7.04, \mathrm{~d}(9.0)$ & Tyr-1 & 2 \\
\hline $\mathrm{OH}$ & & 6.03, br & & 5 \\
\hline Tyr-1 & $169.4, \mathrm{C}$ & & & \\
\hline 2 & $53.8, \mathrm{CH}$ & $4.30, \mathrm{~m}$ & & 3a,3b,Tyr-NH \\
\hline $3 a$ & $34.9, \mathrm{CH}_{2}$ & 3.10 , dd $(14.3,4.2)$ & $2,4,5,9$ & $2,3 b$ \\
\hline $3 b$ & & $2.53, \mathrm{~m}$ & $2,4,5,9$ & $2,3 \mathrm{a}$ \\
\hline 4 & $128.1, \mathrm{C}$ & & & \\
\hline $5 / 9$ & 129.7, CH & $6.90, \mathrm{~d}(8.4)$ & $6,7,8$ & 6,8 \\
\hline $6 / 8$ & $114.9, \mathrm{CH}$ & $6.56, \mathrm{~d}(8.4)$ & $4,5,7,9$ & 5,9 \\
\hline 7 & $155.5, \mathrm{C}$ & & & \\
\hline $\mathrm{NH}$ & & $8.52, \mathrm{~d}(8.9)$ & Thr-1 & 1 \\
\hline Thr-1 & 168.7, C & & & \\
\hline 2 & $54.0, \mathrm{CH}$ & $4.53, \mathrm{~d}(9.6)$ & 1 & Thr-NH \\
\hline 3 & 72.0, $\mathrm{CH}$ & $5.37, \mathrm{~m}$ & 4, Val-1 & 4 \\
\hline 4 & $17.5, \mathrm{CH}_{3}$ & $1.10, \mathrm{~d}(6.5)$ & 2,3 & 3 \\
\hline $\mathrm{NH}$ & & $7.46, \mathrm{~d}(9.5)$ & Gln-1 & 2 \\
\hline Gln-1 & 171.7, C & & & \\
\hline 2 & $52.6, \mathrm{CH}$ & 4.28, ovlp & & \\
\hline $3 a$ & 27.6, $\mathrm{CH}_{2}$ & $1.86, \mathrm{~m}$ & 2,5 & 3a,3b,Gln-NH \\
\hline $3 b$ & & $1.67, \mathrm{~m}$ & 2,5 & $2,3 b, 4$ \\
\hline 4 & $31.5, \mathrm{CH}_{2}$ & 2.10, ovlp & $2,3,5$ & $3 \mathrm{a}, 4$ \\
\hline 5 & 173.7, C & & & $3 a, 3 b$ \\
\hline $\mathrm{NH}$ & & $8.13, \mathrm{~d}(7.7)$ & BTA-1,Gln-2 & \\
\hline $\mathrm{NH}_{2}$ & & $7.27, \mathrm{~s}$ & & 2 \\
\hline BTA-1 & $172.4, \mathrm{C}$ & & & \\
\hline 2 & $37.2, \mathrm{CH}_{2}$ & 2.11, ovlp & $1,3,4$ & 3 \\
\hline 3 & $18.7, \mathrm{CH}_{2}$ & $1.55, \mathrm{~m}$ & $1,2,4$ & 2 \\
\hline 4 & $13.7, \mathrm{CH}_{3}$ & $0.90, \mathrm{t}(7.4)$ & $1,2,3$ & 3 \\
\hline
\end{tabular}

The third metabolite (2) (Fraction D29, peak 6.2) gave an $\mathrm{m} / z$ of $980.4858[\mathrm{M}+\mathrm{Na}]^{+}$ suggesting a molecular formula of $\mathrm{C}_{49} \mathrm{H}_{67} \mathrm{~N}_{9} \mathrm{O}_{11}$ and 21 degrees of unsaturation (Figure S24). Examination of the ${ }^{1} \mathrm{H}$ NMR spectrum showed additional resonances in $\mathbf{2}$ in the region from 7.0 to $7.5 \mathrm{ppm}$ and two shielded doublets $\left(\delta_{\mathrm{H}} 0.88\right.$ and 0.75$)$ that were not present in 1 (Figure S20). Examination of the ${ }^{1} \mathrm{H}$ NMR spectrum and ${ }^{1} \mathrm{H}-{ }^{1} \mathrm{H}$ 2D NMR spectra (COSY, TOCSY, NOESY, Figures S21-S23) established spin systems consistent with the following amino acids: valine, $N$ methyltryptophan, phenylalanine, amino hydroxy piperidone (Ahp), valine, threonine, glutamine, and butyric acid. The sequence of amino acids was estabished via NOE correlations, MS/MS data, 
and analogy to previously characterized micropeptins. An NOE correlation between Ahp-OH $\left(\delta_{\mathrm{H}}\right.$ 5.85) and $\mathrm{H}-9$ of Phe $\left(\delta_{\mathrm{H}} 6.78\right)$ supported that these residues were connected. The MS/MS data showed a fragment $\mathrm{m} / \mathrm{z}$ 443.1931, which supported the fragmentation of Ahp-Phe- $N-\mathrm{MeTrp}-\mathrm{H}_{2} \mathrm{O}$ (Figure S25). This left two positions in the peptide ring to be occupied by valines along with ester formation by threonine and the Gln-BTA side chain. The relative configuration of the Ahp residue was identical to that of $\mathbf{1}$ based on NOE correlations and $\mathbf{2}$ was given the name micropeptin 957.

The absolute configuration of the amino acids in $\mathbf{1}$ and $\mathbf{2}$ was determined by acid hydrolysis of both compounds. Next, we treated the hydrolysates with Marfey's reagent (LFDAA) to generate derivatives, and finally we completed chromatographic comparision of the derivatized hydrolysates to authentic L- and D-amino acid standards (Figures S26 and S27). All amino acids in both $\mathbf{1}$ and $\mathbf{2}$ matched $\mathrm{L}$ standards and the configuration of the Ahp residues in both compouds is proposed based on relative configuration and comparison to previously characterized micropeptins.

Biological Activity. Each micropeptin tested (1, 2, and micropeptin 996) showed the ability to reduce NOS in BV-2 microglial cells following stimulation with bacterial LPS (Figure 3). Approximately a 50\% reduction in NOS was observed for doses of each metabolite at $10 \mu \mathrm{M}$, and significant reduction in NOS was shown at concentrations as low as $0.1 \mu \mathrm{M}$. We tested each metabolite for the ability to inhibit the protease plasmin with the rationale that perhaps the antiinflammatory activity was the result of the inhibition of this protease in the cell. The activation of plasminogen to the protease plasmin occurs in cellular inflammatory responses and plasminogen activation has shown the ability to activate microglial cells. ${ }^{18,19}$ Additionally, other micropeptins have shown the ability to inhibit plasmin. ${ }^{20}$ However, in vitro enzyme inhibition assays did not show inhibition when concentrations of the micropeptins were tested up to $10 \mu \mathrm{M}$ concentrations (Figure S28).

In this report, we have isolated and characterized two new micropeptins (1 and $\mathbf{2})$, and we have evaluated the ability of three micropeptins $(\mathbf{1}, \mathbf{2}$, micropeptin 996) to reduce inflammation in BV-2 microglial cells. Micropeptins are a large class of cyanobacterial peptides with over 82 variants, ${ }^{7}$ and a complicated nomenclature which includes alternative names to micropeptin such as cyanopeptolin, aeruginopeptin, anabaenopeptilide, oscillapeptilide, oscillapeptin among several others. ${ }^{7}$ However, despite the many names, the chemistry is more consistent in this group as the class is characterized by the 3-amino-6-hydroxy-2-piperidone (Ahp) residue and an ester linkage formed by the $\beta$-hydroxy group of threonine and the carboxy group of the terminal amino acid. There are four other ring amino acids (six total), which can be variable and the penultimate residue (from the point of view of biosynthesis) is $N$-methylated. There are two additional residues not in the ring: one an amino acid and the other a fatty acid. These characteristics are also observed in $\mathbf{1}$ and 2. Intriguingly, while these metabolites are generally thought to be sequestered to cyanobacterial metabolism, a recent cyanopeptolin isolated from a Streptomyces olivochromogenes strain provokes thoughts as to the evolutionary history of this class of molecules. ${ }^{21}$ A consistent biological activity observed in this class is protease inhibition in contrast to the phosphatase inhibition observed from microcystins. ${ }^{22}$ For instance, micropeptin 996 was previously shown as a potent inhibitor of chymotrypsin with an $\mathrm{IC}_{50}$ of $0.64 \mu \mathrm{M} .{ }^{16}$ Micropeptin T2 showed potent inhibition of plasmin $\left(\mathrm{IC}_{50}=0.1 \mu \mathrm{g} / \mathrm{mL}\right)$, while micropeptin $\mathrm{T} 1$ showed no ability to inhibit this protease $\left(\mathrm{IC}_{50}>100 \mu \mathrm{g} / \mathrm{mL}\right) .{ }^{20}$ The difference between the two metabolites was a substitution of lysine in T2 instead of the tyrosine in T1 (in the same amino acid position as tyrosine in 1). We observed no plasmin inhibition from 1, 2, or micropeptin 996 and this may be due to specific amino acid residues conferring this activity to specific micropeptins. Additional structure-activity relationship studies should prove illuminating with respect to protease inhibition. 
Other micropeptins such as kyanamide, symplostatin 5, and tutuilamides A-C all showed potent inhibition of elastase. ${ }^{17,23,24}$

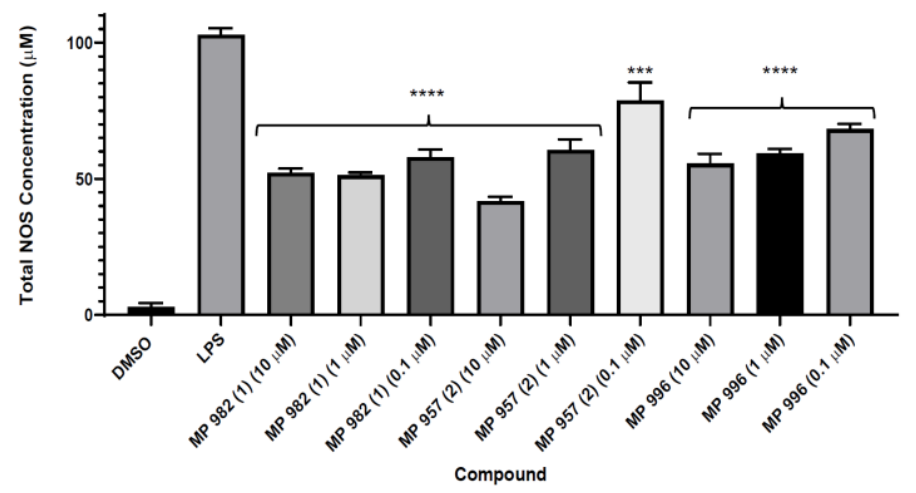

Figure 3. Anti-inflammatory activity of micropeptin 982 (MP 982) 1, micropeptin 957 (MP 957) 2, and micropeptin 996 (MP 996) tested against BV-2 murine microglial cells. All data is expressed as mean \pm standard error $(n=3)$, and the significance was reported by analysis of variance (ANOVA) followed with Dunnett's multiple comparison procedure. Significance $(\alpha=$ $0.05)$ as compared with LPS, $p \leq 0.0002(* * *)$ and $p \leq 0.0001(* * * *)$.

Symplostatin 5 additionally alleviated inflammation in an epithelial lung airway model system. ${ }^{22}$ We observed a reduction in inflammation in microglial cells after treatment with the micropeptins reported in this study and further explorations of their mechanism of action in microglial cells in warranted. For realistic therapeutic development of CNS drugs, transport through the blood-brain barrier is essential. While microcystins have been shown to rely on transportation through organic anionic transporters (OATs) to move into cells, ${ }^{25}$ less is known about the same transport of micropeptins. However, it will be essential to determine the ability of micropeptins to cross the $\mathrm{BBB}$ to be realistic agents for reducing neuroinflammation. In addition to the fraction (D29) that was further mined in this report, there are several other fractions of interest that had the ability to reduce NOS levels in LPS-stimulated microglial cells (Figure S3). Fraction D29 was chosen for further purification because it showed the strongest reduction in NOS when tested at $10 \mu \mathrm{g} / \mathrm{mL}$ and also showed no significant cytotoxic effects at the same concentration.

\section{CONCLUSION}

The metabolite profiling approach (LC-MS/MS molecular networking) was implemented in our workflow and we quickly identified the micropeptin class in our active fraction. This mass spectrometry-guided approach can be paired with bioassay data to identify likely bioactive molecules in samples with many analytes. ${ }^{26}$ Molecular networking has been used to describe the chemical space in cyanobacterial harmful algal blooms, ${ }^{27,28}$ and innovative approaches using this technology will continue to increase the efficiency of therapeutic discovery efforts. There are many other likely micropeptins in this active sample (Figure S4), and further isolations will allow for structure-activity relationship studies to be carried out. There were clearly potent cytotoxins as well in the prefractionated library, which may be of interest as potential chemotherapeutics or may be explored for their environmental toxicity (Figure S2). High content and information-rich mass spectrometry workflows paired with additional bioassays will be necessary to fully exploit the potential of the wealth of metabolites in the prefractionated library.

\section{MATERIALS AND METHODS}


General Experimental Procedures. Optical rotations were acquired using a Jasco P-2000 polarimeter. UV spectra were measured using a Beckman Coulter DU-800 spectrophotometer. NMR spectra were recorded using a Varian $500 \mathrm{MHz}$ instrument. The chemical shifts reported for 1, 2, and micropeptin 996 were referenced to the residual solvent peaks of DMSO- $d_{6}\left(\delta_{\mathrm{H}} 2.50\right.$ and $\delta_{\mathrm{C}}$ 39.5). HRESIMS analysis was peformed using an AB SCIEX TripleTOF 4600 mass spectrometer with Analyst software. MS/MS data were recorded on this same instrument using the product ion function. LC-MS/MS was performed using a ThermoFisher LTQ XL mass spectrometer with an electrospray ionization (ESI) source. Semi-preparative and analytical HPLC was carried out using a Dionex UltiMate 3000 HPLC system equipped with a micro vacuum degasser, an autosampler, and a diode-array detector.

Collection and Processing of Cyanobacterial Biomass into Prefraction Library. Biomass was collected from a holding lagoon at the Muskegon County Wastewater Management facility on Maple Island Road, Muskegon, Michigan, USA and concentration of biomass was completed as previously described. ${ }^{10}$ The biomass was lyophilized and sent to AnalytiCon Discovery (Potsdam, Germany) for library fractionation. $10 \mathrm{~kg}$ of lyophilized biomass powder was repeatedly extracted methanol, and separation over HP-20 eluting in 10\% MeOH steps resulted in a medium polarity fraction. Next preparative HPLC generated the pre-fractionated library, which was partitioned into deep well plates for initial biological testing.

LC-MS/MS-Based Molecular Networking. Fraction D29 was subjected to LC-MS/MS analysis with a specific scan event recording MS/MS spectra in data-dependent acquisition mode on a ThermoFisher LTQ XL mass spectrometer with an electrospray ionization (ESI) source coupled to a Dionex UltiMate 3000 HPLC system equipped with a micro vacuum degasser, an autosampler, and a diode-array detector. A Kinetex $5 \mu \mathrm{m} \mathrm{C18} \mathrm{column}(150 \times 4.6 \mathrm{~mm})$ was used for separation of analytes. The LC method consisted of a linear gradient from $15 \%$ to $100 \% \mathrm{CH}_{3} \mathrm{CN}$ in water + $0.1 \%$ formic acid over $20 \mathrm{~min}$, followed by an isocratic period at $100 \% \mathrm{CH}_{3} \mathrm{CN}$ of $5 \mathrm{~min}$. The flow rate was held constant at $0.4 \mathrm{~mL} / \mathrm{min}$. The $\mathrm{MS}$ spray voltage was $3.5 \mathrm{kV}$ with a capillary temperature of $325^{\circ} \mathrm{C}$. For the MS/MS component, the CID isolation width was 1.0 and the collision energy was $35.0 \mathrm{eV}$. The raw data files were converted to mzXML format using MSConvert from the ProteoWizard suite (http://proteowizard.sourceforge.net/tools.shtml). The molecular network was generated using the online platform at Global Natural Products Social Molecular Networking website (gnps.ucsd.edu) [27]. The data were processed by removing all MS/MS fragment ions within +/- 17 Da of the precursor $m / z$. MS/MS spectra were filtered by choosing only the top 6 fragment ions in the $+/-50 \mathrm{Da}$ window throughout the spectrum. The precursor ion mass tolerance was set to 2.0 Da with a MS/MS fragment ion tolerance of $0.5 \mathrm{Da}$. A network was then created where edges were filtered to have a cosine score above 0.6 and more than 2 matched peaks. The spectra in the network were then searched against GNPS' spectral libraries. The library spectra were filtered in the same manner as the input data. All matches kept between network spectra and library spectra were required to have a score above 0.6 and at least 2 matched peaks. The network was visualized using the Browser Network Visualizer tool available on the gnps website, ${ }^{29}$ and then imported into the program Cytoscape for additional analysis.

Isolation of 1 and 2. Fraction D29 from the prefractionated library was subjected to reversed phase semi-preparative HPLC using a Kinetex $5 \mu \mathrm{m} \mathrm{C18} \mathrm{column}(250 \times 10 \mathrm{~mm})$ and an isocratic method. Mobile phase: $65 \% \mathrm{CH}_{3} \mathrm{CN} / 35 \% \mathrm{H}_{2} \mathrm{O}$ with $0.05 \%$ formic acid added to each solvent and flow rate of $3 \mathrm{~mL} / \mathrm{min}$. Seven HPLC peaks (1-7) were collected and subjected to the antiinflammatory assay and an evaluation of purity using ${ }^{1} \mathrm{H}$ NMR and LC-MS. This first purification resulted in the isolation of $14 \mathrm{mg}$ of micropeptin $996\left(\mathrm{t}_{\mathrm{R}}, 26.5 \mathrm{~min}\right.$, peak 7). Peak 6 ( $\left.\mathrm{t}_{\mathrm{R}}, 25 \mathrm{~min}\right)$ 
was further purified using a YMC $5 \mu \mathrm{m}$ Chiral ART Cellulose-SB column $(250 \mathrm{x} 4.6 \mathrm{~mm}) \mathrm{using}$ an isocratic method. Mobile phase: $65 \% \mathrm{CH}_{3} \mathrm{CN} / 35 \% \mathrm{H}_{2} \mathrm{O}$ with $0.05 \%$ formic acid added to each solvent and flow rate of $1 \mathrm{~mL} / \mathrm{min}$. Final purification resulted in the isolation of $12 \mathrm{mg}$ of $1\left(t_{R}\right.$, $5.25 \mathrm{~min}$, peak 6.1) and $2 \mathrm{mg}$ of $2\left(t_{R}, 10.75 \mathrm{~min}\right.$, peak 6.2).

Micropeptin 982 (1): colorless oil; $[\alpha]^{23} \mathrm{D}-65\left(c\right.$ 0.1, MeOH); UV $(\mathrm{MeOH}) \lambda_{\max }(\log \varepsilon) 228$ (4.8), 278 (4.1) nm; ${ }^{1} \mathrm{H}$ NMR (500 MHz, DMSO- $\left.d_{6}\right)$, and ${ }^{13} \mathrm{C}$ NMR (125 MHz, DMSO$d_{6}$ ), see Table 1 ; HRESIMS $m / z$, $1005.4698[\mathrm{M}+\mathrm{Na}]^{+}$(calcd for $\mathrm{C}_{51} \mathrm{H}_{66} \mathrm{~N}_{8} \mathrm{O}_{12} \mathrm{Na}$, 1005.4698).

Micropeptin 957 (2): colorless oil; $[\alpha]^{23} \mathrm{D}-23$ (c 0.1, MeOH); UV (MeOH) $\lambda_{\max }(\log \varepsilon) 224$ (4.8), 274 (3.9) nm; ${ }^{1} \mathrm{H}$ NMR (500 MHz, DMSO- $d_{6}$ ), see Table S1; HRESIMS $\mathrm{m} / z$ $980.4858[\mathrm{M}+\mathrm{Na}]^{+}$(calcd for $\mathrm{C}_{49} \mathrm{H}_{67} \mathrm{~N}_{9} \mathrm{O}_{11} \mathrm{Na}, 980.4858$ ).

Marfey's Analysis. To determine the absolute configuration of the $\alpha$-amino acids in $\mathbf{1}$ and 2, 0.5 mg of each compound was reconstituted in $0.5 \mathrm{~mL}$ of $6 \mathrm{~N} \mathrm{HCl}$ and heated at $110^{\circ} \mathrm{C}$ for $15 \mathrm{~h}$. The hydrolysate was dried, reconstituted in $300 \mu \mathrm{L}$ of $1 \mathrm{M} \mathrm{NaHCO}_{3}$ solution, and treated with $50 \mu \mathrm{L}$ of $1 \mathrm{mg} / \mathrm{ml}$ solution of $\mathrm{N}-\alpha$-(2,4-dinitro-5-fluorophenyl)-L-alanine amide (L-FDAA) in acetone, followed by heating at $40{ }^{\circ} \mathrm{C}$ for $1 \mathrm{~h}$. Next the mixture was cooled to room temperature and quenched with $100 \mu \mathrm{L}$ of $1 \mathrm{~N} \mathrm{HCl}$. The hydrolysate was dried and reconstituted in $200 \mu \mathrm{L}$ of $\mathrm{CH}_{3} \mathrm{CN}$ and filtered through a $0.2 \mu \mathrm{m}$ filter. The hydrolysate and the L-FDAA derivatized $\alpha$-amino acid standards were subjected to HPLC analysis $\left(20 \% \mathrm{H}_{2} \mathrm{O} / \mathrm{CH}_{3} \mathrm{CN}+0.1 \%\right.$ FA to $50 \% \mathrm{H}_{2} \mathrm{O}$ / $\mathrm{CH}_{3} \mathrm{CN}+0.1 \%$ FA over $30 \mathrm{~min}$ and then back to initial conditions from 31-36 min; Kinetex C18 column, $150 \times 4.6 \mathrm{~mm}$, flow rate $0.6 \mathrm{~mL} / \mathrm{min}$ ). The retention time (min) of the hydrolysate of $\mathbf{1}$ matched L-Val (20.4; D-Val, 23.1), L- $N$-MePhe (23.6; D- $N$-MePhe, 23.9), L-Phe (23.3; D-Phe, 25.1), L-Tyr (18.4, D-Tyr, 19.6), L-Thr (12.5; D-Thr, 15.3; L-allo-Thr, 12.7; D-allo-Thr, 13.8), and L-Gln (11.6; D-Gln, 12.0). The retention times (min) of the hydrolysate of 2 matched L-Val (20.4; D-Val, 23.1), L- $N$-MeTrp (21.6; D- $N$-MeTrp, 22.4), L-Phe (23.3; D-Phe, 25.1), L-Thr (12.5; D-Tyr, 15.3; L-allo-Thr, 12.7; D-allo-Thr, 13.8), and L-Gln (11.6; D-Gln, 12.0).

Biological Assays. BV-2 murine microglial cells were cultured as previously described. ${ }^{6}$ The cytotoxicity of the library fractions and pure compounds to the cells was measured using the CellTiter-Glo® Luminescent Cell Viability Assay (CTG, Promega, Fitchburg, WI). BV-2 cells were treated with trypsin and seeded in a white-walled 96-well plate (Corning, Corning, NY) at 100,000 cells $/ \mathrm{mL}$ in DMEM/F-12 media. Cells were allowed to adhere for $24 \mathrm{~h}$ in the incubator followed by treatment with the fractions at $10 \mu \mathrm{g} / \mathrm{mL}$ concentrations and eventually pure compounds at final concentrations of $10 \mu \mathrm{M}, 1 \mu \mathrm{M}$, and $0.1 \mu \mathrm{M}$. After dosing, the cells were incubated with fractions or pure compounds for $24 \mathrm{~h}$. Following incubation, the cell viability was measured following manufacturer's protocols. The CTG buffer and substrate were combined, and $100 \mu \mathrm{L}$ of mixed reagent was added to each well followed by two minutes of slow shaking on an orbital shaker, then 10 minutes of non-shaking equilibration time. The luminescence was measured using a SpectraMax M2 Plate Reader. Cell viability was then reported as a percent of vehicle control (DMSO). In order to test for anti-inflammatory activity, the Griess assay was used. The Griess assay reagent kit was purchased from Promega Corp (Fitchburg, WI, USA). BV-2 cells were plated in a 24 -well plate at 100,000 cells $/ \mathrm{mL}$ in complete media. Cells were treated with fractions or pure compounds for $1 \mathrm{~h}$ at the same concentrations used for the cell viability assays. After incubation, BV-2 microglia were exposed to (LPS) at $1 \mu \mathrm{g} / \mathrm{mL}$ for $23 \mathrm{~h}$. After incubation, $50 \mu \mathrm{L}$ aliquots were taken from each well and transferred to a clear 96-well plate where Griess reagents were added for total nitric oxide concentration determination compared to the control 
wells of DMSO. Statistical significance was determined using a One-way ANOVA followed by a Dunnett's post hoc test, and analysis was performed using the program Prism (San Diego, CA).

Funding. Certain spectroscopic and spectrometric measurements were made using equipment and services available through the RI-INBRE Centralized Research Core Facility at the University of Rhode Island, which is supported by the Institutional Development Award (IDeA) Network for Biomedical Research Excellence from the National Institute of General Medical Sciences of the National Institutes of Health under grant number P20GM103430.

Acknowledgments. We thank Dr. Navindra Seeram at the University of Rhode Island College of Pharmacy for providing the BV-2 cells used in these studies. We also thank Chad Hummell, David Coho, Clinton Cole, and Ross Youngs for assistance with the Biosortia sample library selection and transport.

\section{ASSOCIATED CONTENT}

Supporting Information. The Supporting Information is available free of charge on the ACS Omega website. Table S1: NMR data for micropeptin 957 (2), Figure S1: Structures of micropeptins 982 (1), 957 (2), and 996, Figure S2: Cell viability of Biosortia chromatography fractions tested against BV-2 murine microglial cells, Figure S3: Ability of Biosortia chromatography fractions to reduce nitric oxides species (NOS) in BV-2 murine microglial cells, Figure S4: Full LC-MS/MS molecular network, Figure S5: HPLC isolation of compounds in chromatography fraction D29, Figure S6: Final purification of compounds 1 (6.1) and 2 (6.2) from fraction D29 peak 6, Figures S7-S10: ${ }^{1} \mathrm{H}$ NMR, ${ }^{13} \mathrm{C}$ NMR, HRESIMS, and MS/MS data for micropeptin 996, Figures S11-S19: ${ }^{1} \mathrm{H}$ NMR, ${ }^{13} \mathrm{C}$ NMR, HSQC, HMBC, COSY, TOCSY, NOESY, HRESIMS, and MS/MS data for micropeptin 982 (1), Figures S20-S25: ${ }^{1} \mathrm{H}$ NMR, COSY, TOCSY, NOESY, HRESIMS, and MS/MS of micropeptin 957 (2), Figures S26 and S27: Marfey's analysis of $\mathbf{1}$ and 2, Figure S28: Dose-response of micropeptin 996, 1, and $\mathbf{2}$ tested for plasmin inhibition.

Conflicts of Interest. The authors declare no conflict of interest.

\section{AUTHOR INFORMATION}

Corresponding Author. email: mbertin@uri.edu; Tel: 1-401-874-5016; ORCID: 0000-00022200-0277

Author Information. Riley D. Kirk, email: rileykirk@uri.edu, ORCID: 0000-0001-5324-7857; Haiyin He, email: haiyin_he@yahoo.com; Paul G. Wahome, email: wahomepg@gmail.com; ShiBiao Wu, email: shibiao.wu@gmail.com; Guy Carter, email: gtc9531@gmail.com, ORCID: 0000-0002-9386-067X.

Author Contributions. Conceptualization, M.J.B. and G.T.C.; methodology, R.D.K., H.H., P.G.W., S.W., and M.J.B; formal analysis, R.D.K.; writing - original draft preparation, M.J.B.; writing-review and editing, R.D.K., G.T.C., and M.J.B. All authors have read and agreed to the published version of the manuscript.

\section{REFERENCES}

1. Ellis, A.; Bennett, D. L. Neuroinflammation and the generation of neuropathic pain. Br. J. Anaesth. 2013, 111, 26-37. 
2. DiBonaventura, M. D.; Sadosky, A.; Concialdi, K.; Hopps, M.; Kudel, I.; Parsons, B.; Cappelleri, J. C.; Hlavacek, P.; Alexander, A. H.; Stacey, B. R.; Markman, J. D.; Farrar, J. T. The prevalence of probable neuropathic pain in the US: results from a multimodal general-population health survey. J. Pain Res. 2017, 10, 2525-2538.

3. $\quad$ Freynhagen, R.; Baron, R.; Tölle, T.; Stemmler, E.; Gockel, U.; Stevens, M.; Maier, C. Screening of neuropathic pain components in patients with chronic back pain associated with nerve root compression: a prospective observational pilot study (MIPORT). Curr. Med. Res. Opin. 2006, 22, 529-537.

4. Khandelwal, P. J.; Herman, A. M.; Moussa, C. E. H. Inflammation in the early stages of neurodegenerative pathology. J. Neuroimmunol. 2011, 238, 1-11.

5. Stephenson, J.; Nutma, E.; van der Valk, P.; Amor, S. Inflammation in CNS neurodegenerative diseases. Immunology 2018, 152, 204-219.

6. Kirk, R. D.; Picard, K.; Christian, J. A.; Johnson, S. L.; DeBoef, B.; Bertin, M. J. Unnarmicin D, an anti-inflammatory cyanobacterial metabolite with $\delta$ and $\mu$ opioid binding activity discovered via a pipeline approach designed to target neurotherapeutics. ACS Chem. Neurosci. 2020, 11, 4478-4488.

7. Welker, M.; Von Döhren, H. Cyanobacterial peptides - Nature's own combinatorial biosynthesis. FEMS Microbiol. Rev. 2006, 30, 530-563.

8. He, J.; Li, G.; Chen, J.; Lin, J.; Zeng, C.; Chen, J.; Xie, P. Prolonged exposure to low-dose microcystin induces nonalcoholic steatohepatitis in mice: a systems toxicology study. Arch. Toxicol. 2017, 91, 465-480.

9. Falconer, I. R.; Beresford, A. M.; Runnegar, M. T. Evidence of liver damage by toxin from a bloom of the blue- green alga, Microcystis aeruginosa. Med. J. Aust. 1983, 1, 511-514.

10. He, H.; Wu, S.; Wahome, P. G.; Bertin, M. J.; Pedone, A. C.; Beauchesne, K. R.; Moeller, P. D. R.; Carter, G. T. Microcystins containing doubly homologated tyrosine residues from a Microcystis aeruginosa bloom: structures and cytotoxicity. J. Nat. Prod. 2018, 81, 13681375.

11. He, H.; Bertin, M. J.; Wu, S.; Wahome, P. G.; Beauchesne, K. R.; Youngs, R. O.; Zimba, P. V.; Moeller, P. D. R.; Sauri, J.; Carter, G. T. Cyanobufalins: cardioactive toxins from cyanobacterial blooms. J. Nat. Prod. 2018, 81, 2576-2581.

12. Grkovic, T.; Akee, R. K.; Thornburg, C. C.; Trinh, S. K.; Britt, J. R.; Harris, M. J.; Evans, J. R.; Kang, U.; Ensel, S.; Henrich, C. J.; Gustafson, K. R.; Schneider, J. P.; O’Keefe, B. R. National Cancer Institute (NCI) program for natural products discovery: rapid isolation and identification of biologically active natural products from the NCI prefractionated library. ACS Chem. Biol. 2020, 15, 1104-1114.

13. Yang, J. Y.; Sanchez, L. M.; Rath, C. M.; Liu, X.; Boudreau, P. D.; Bruns, N.; Glukhov, E.; Wodtke, A.; de Felicio, R.; Fenner, A.; Wong, W. R.; Linington, R. G.; Zhang, L.; Debonsi, H. M.; Gerwick, W. H.; Dorrestein, P. C. Molecular networking as a dereplication strategy. J. Nat. Prod. 2013, 76, 1686-1699.

14. Le Manach, S.; Duval, C.; Marie, A.; Djediat, C.; Catherine, A.; Edery, M.; Bernard, C.; Marie, B. Global metabolomic characterizations of Microcystis spp. highlights clonal diversity in natural bloom-forming populations and expands metabolite structural diversity. Front. Microbiol. 2019, 10, 791.

15. Kust, A.; Řehákova, K.; Vrba, J.; Maicher, V.; Mareš, J.; Hrouzek, P.; Chiriac, M. -C.; Benedová, Z.; Tesařova, B.; Saurav, K. Insight into unprecedented diversity of cyanopeptides in eutrophic ponds using an MS/MS networking approach. Toxins 2020, 12, 561. 
16. Strangman, W. K.; Stewart, A. K.; Herring, M. C.; Wright, J. L. C. Identification of the new chymotrypsin inhibitor micropeptin 996 by metabolomics-guided analysis. Tetrahedron Lett. 2018, 59, 934-937.

17. Keller, L.; Canuto, K. M.; Liu, C.; Suzuki, B. M.; Almaliti, J.; Sikander, A.; Naman, C. B.; Glukhov, E.; Luo, D.; Duggan, B. M.; Luesch, H.; Koehnke, J.; O’Donoghue, A. J.; Gerwick, W. H. Tutuilamides A-C: vinyl-chloride-containing cyclodepsipeptides from marine cyanobacteria with potent elastase inhibitory properties. ACS Chem. Biol. 2020, 15, 751-757.

18. Heissig, B.; Salama, Y.; Takahashi, S.; Osada, T.; Hattori, K. The multifaceted role of plasminogen in inflammation. Cell. Signal. 2020, 75, 109761.

19. Mehra, A.; Ali, C.; Parcq, J.; Vivien, D.; Docagne, F. The plasminogen activation system in neuroinflammation. Biochim. Biophys. Acta 2016, 1862, 395-402.

20. Kodani, S.; Suzuki, S.; Ishida, K.; Murakami, M. Five new cyanobacterial peptides from water bloom materials of lake Teganuma (Japan). FEMS Microbiol. Lett. 1999, 178, 343348.

21. Kodani, S.; Komaki, H.; Hemmi, H.; Miyake, Y.; Kaweewan, I.; Dohra, H. Streptopeptolin, a cyanopeptolin-type peptide from Streptomyces olivochromogenes. ACS Omega 2018, 3, 8104-8110.

22. MacKintosh, C.; Beattie, K. A.; Klumpp, S.; Cohen, P.; Codd, G. A. Cyanobacterial microcystin-LR is a potent and specific inhibitor of protein phosphatases 1 and $2 \mathrm{~A}$ from both mammals and higher animals. FEBS Lett. 1990, 264, 187-192.

23. Ozaki, K.; Iwasaki, A.; Suenaga, K.; Teruya, T. Kyanamide, a new Ahp-containing depsipeptide from marine cyanobacterium Caldora penicillata. Tetrahedron 2019, 75, 3382-3386.

24. Salvador, L. A.; Taori, K.; Biggs, J. S.; Jakoncic, J.; Ostrov, D. A.; Paul, V. J.; Luesch, H. Potent elastase inhibitors from cyanobacteria: structural basis and mechanisms mediating cytoprotective and anti-inflammatory effects in bronchial epithelial cells. $J$. Med. Chem. 2013, 56, 1276-1290.

25. Fischer, W. J.; Altheimer, S.; Cattori, V.; Meier, P. J.; Dietrich, D. R.; Hagenbuch, B. Organic anion transporting polypeptides expressed in liver and brain mediate uptake of microcystin. Toxicol. Appl. Pharmacol. 2005, 203, 257-263.

26. Nothias, L. -F.; Nothias-Esposito, M.; da Silva, R.; Wang, M.; Protsyuk, I.; Zhang, Z.; Sarvepalli, A.; Leyssen, P.; Touboul, D.; Costa, J.; Paolini, J.; Alexandrov, T.; Litaudon, M.; Dorrestein, P. C. Bioactivity-based molecular networking for the discovery of drug leads in natural product bioassay-guided fractionation. J. Nat. Prod. 2018, 81, 758-767.

27. Teta, R.; Della Sala, G.; Glukhov, E.; Gerwick, L.; Gerwick, W. H.; Mangoni, A.; Costantino, V. Combined LC-MS/MS and molecular networking approach reveals new cyanotoxins from the 2014 cyanobacterial bloom in Green Lake, Seattle. Environ. Sci. Technol. 2015, 49, 14301-14310.

28. Via, C. W.; Glukhov, E.; Costa, S.; Zimba, P. V.; Moeller, P. D. R.; Gerwick, W. H.; Bertin, M. J. The metabolome of a cyanobacterial bloom visualized by MS/MS-based molecular networking reveals new neurotoxic smenamide analogs (C, D, and E). Front. Chem. 2018, 6, 316.

29. Wang, M.; Carver, J. J.; Phelan, V. V.; Sanchez, L. M.; Garg, N.; Peng, Y.; Nguyen, D. D., et al. Sharing and community curation of mass spectrometry data with Global Natural Products Social Molecular Networking. Nat. Biotechnol. 2016, 34, 828-837.

\section{FOR TABLE OF CONTENTS ONLY}




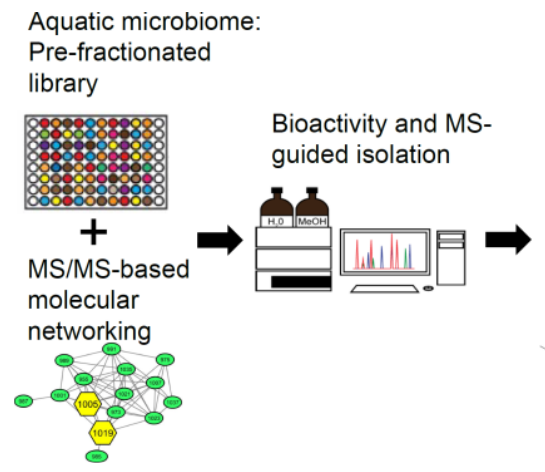

New anti-inflammatory

micropeptins
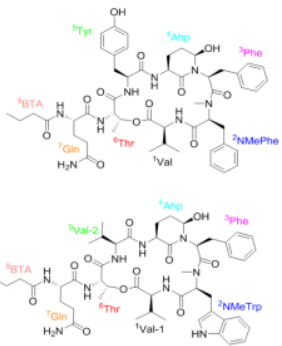